\title{
DETERMINAN ISLAMIC HUMAN DEVELOPMENT INDEX (IHDI) PROVINSI JAWA TIMUR TAHUN 2001-20161
}

\section{RENI MUSTIKA PUTRI}

Departemen Ekonomi Syariah - Fakultas Ekonomi dan Bisnis - Universitas Airlangga Email: reni.mustika.putri@gmail.com

Karjadi Mintaroem

Departemen Ekonomi Syariah - Fakultas Ekonomi dan Bisnis - Universitas Airlangga Email: mintaroem@yahoo.com

\begin{abstract}
:
This study aimed to determine the effect of economic growth, government expenditure, and ZIS distribution on IHDI in East Java in 2001-2016. The research method using quantitative approach by usingOrdinary Least Square (OLS) to see the elasticity of independent variables to dependent variables. The result of statistical test analysis showed that three of four independent variables had a positive and significant value on IHDI, which were: economic growth, goverment expenditure on education, and government expenditure on health. Zakat, infaq, sadaqah variables have nosignificant effect on IHDI.

Keywords: Economic Growth, Education Expenditure, Health Expenditure, ZIS Distribution, Islamic Human Development Index.
\end{abstract}

\section{PENDAHULUAN}

Mengelola dan mengolah sumber daya alam tentu memerlukan keterampilan dan wawasan dalam diri manusia. Kedua sumber daya tersebut merupakan komponen yang menentukan pembangunan yang saling mengikat bahkan tidak dapat dipisahkan. Islam telah menjelaskan bahwa manusia memiliki tanggung jawab dari Allah SWT untuk memakmurkan bumi dengan akal dan pikiran yang dimiliki. Sesuai dengan firman Allah SWT berikut:

Artinya: "Dan kepada Tsamud (Kami utus) saudara mereka Shaleh. Shaleh berkata: "Hai kaumku, sembahlah Allah SWT, sekali-kali tidak ada bagimu Tuhan selain Dia. Dia telah menciptakan kamu dari bumi (tanah) dan menjadikan kamu pemakmurnya, karena itu mohonlah
ampunan-Nya, kemudian bertobatlah kepada-Nya, Sesungguhnya Tuhanku amat dekat (rahmat-Nya) lagi memperkenankan (doa hamba-Nya)". Q.S. Hud (11): 61

Pengukuran kualitas sumber daya manusia di hampir seluruh negara sampai dengan saat ini menggunakan Human Development Index (HDI) yang telah disusun oleh United Nations Development Program (UNDP). Menurut UNDP, HDI merupakan alat pengukur paling komprehensif yang digunakan oleh hampir seluruh negara. HDI menggunakan empat instrumen dalam perhitungannya yaitu: angka harapan hidup, angka melek huruf, rata-rata lama sekolah dan besarnya pengeluaran perkapita pada suatu negara (www.bps.go.id). Sedangkan Pengukuran kualitas sumber

\footnotetext{
${ }^{1}$ Jurnal ini merupakan bagian dari skripsi Renl Mustlka Putrl, NIM: 04131433011, yang diuji pada tanggal 22 Oktober 2018.
} 
Putri, et al/Jurnal Ekonomi Syariah Teori dan Terapan Vol. 6 No. 7 Juli 2019: 1410-1420; DETERMINAN ISLAMIC HUMAN DEVELOPMENT INDEX (IHDI) PROVINSI JAWA TIMUR TAHUN 2001-2016

daya manusia menurut perspektif Islam bukan hanya dilihat dengan tiga aspek saja namun haruslah lebih mendalam meliputi segala aspek jasmani dan aspek rohani yang sesuai dengan maqashid syariah, sebab tujuan tertinggi dalam pembangunan manusia seharusnya adalah pencapaian tingkat kesejahteraan manusia akan terpenuhinya kebutuhan dasar agar manusia dapat mencapai keberkahan di dunia dan akhirat (al-falah).

Variabel yang dapat mempengaruhi pembangunan manusia salah satunya adalah pertumbuhan ekonomi. UNDP melihat bahwa pertumbuhan ekonomi dapat berdampak pada kemampuan suatu negara untuk melaksanakan pembangunan manusia secara berkelanjutan. Keduanya memang tidak memiliki keterikatan secara langsung, akan tetapi pertumbuhan ekonomi dapat menjadi alat penggerak dalam peningkatan kualitas sumberdaya manusia, begitu pula sebaliknya.

Pertumbuhan ekonomi dapat ditunjukan melalui Pendapatan Domestik Bruto (PDB). Pengukuran pertumbuhan ekonomi dengan PDB hampir digunakan diseluruh negara untuk melihat kondisi ekonomi dan menentukan kebijakan dengan menggunakan struktur dan komponen yang sama. PDB sendiri merupakan jumlah nilai tambah atau balas jasa faktor produksi yang dihasilkan oleh seluruh unit usaha dalam suatu negara. Perhitungan PDB untuk wilayah regional (Provinsi/Kabupaten/Kota) disebut dengan Produk Domestik Regional Bruto/PDRB (Mankiw, 2012).

Selain PDRB terdapat komponen yang juga sangat berpengaruh dalam pembangunan manusia adalah Belanja modal manusia yang meliputi aspek pendidikan dan kesehatan. Baeti (2013:89) menyatakan bahwa tingkat pendidikan dan kesehatan individu penduduk merupakan faktor dominan yang perlu mendapat prioritas utama dalam peningkatan kualitas sumber daya manusia. Tingkat pendidikan dan kesehatan penduduk yang tinggi akan menentukan kemampuan untuk menyerap dan mengelola sumber-sumber pembangunan ekonomi baik teknologi sampai kelembagaan dalam upaya meningkatkan tingkat kesejahteraan penduduk.

Variabel lain yang dapat mempengaruhi IHDI adalah distribusi dana zakat, Infak dan sedekah. Zakat, Infak dan sedekah dimasa sekarang menjadi instrumen alternatif dalam pembangunan manusia. Islam menganggap bahwa harta kekayaan merupakan hak bagi mereka yang membutuhkan bukan sebagai sesuatu yang hanya dimiliki oleh pihak pemberi, sehingga harta harus terus mengalir dan tersalurkan. Instrumen zakat khususnya, pembayaran ini bersifat wajib bagi seluruh Muslim yang berpendapatan diatas ambang batas tertentu, merupakan salah satu bentuk pemindahan kekayaan terbesar bagi masyarakat miskin dan membutuhkan. 
Di beberapa negara ZIS merupakan salah satu instrumen yang diabaikan oleh organisasi- organisasi pembangunan, padahal ZIS memiliki potensi yang sangat besar untuk berkontribusi pada pencapaian peningkatan kualitas sumberdaya manusia. ZIS pada akhir tujuannya akan memberikan kesempatan bagi penerima dana ZIS untuk mengubah standar hidup mereka menjadi lebih baik baik. Berbeda dengan negara Indonesia, dengan adanya UU No 23 Tahun 2011 tentang pengelolaan zakat, infak dan sedekah membuat penghimpunan dan penyaluran ZIS menjadi lebih terstruktur dan memiliki pakem yang jelas sehingga lebih mudah mencapai tujuan.

\section{LANDASAN TEORI}

Islamic-Human Development Index (I-HDI)

I-HDI adalah alat yang digunakan untuk mengukur pembangunan manusia dalam perspektif Islam. I-HDI mengukur pencapaian tingkat kesejahteraan manusia dengan terpenuhinya kebutuhan (maslahah) dasar agar manusia dapat hidup bahagia di dunia dan akhirat.

Menurut Anto (2009), indeks yang diusulkan untuk mengukur semua dimensi maqashid syariah dalam membentuk I-HDI ada 5, yaitu indexad dien yang mewakili dimensi agama, indexan-nafs yang mewaili dimensi umur panjang dan sehat, indexal-'aql yang mewakili dimensi pengetahuan, indexan nasl yang mewakili dimensi keluarga dan keturunan, dan indexal-maal yang mewakili dimensi pendapatan.

\section{Pertumbuhan Ekonomi}

Menurut Kuznet dalam Todaro (2000:144), pertumbuhan ekonomi memiliki arti sebagai peningkatan kapasitas ekonomi dalam jangka panjang dari suatu negara untuk meyediakan barang ekonomi pada penduduknya.

Menurut Naf'an (2014:237) dalam berbagai literatur tentang ekonomi Islam, pertumbuhan ekonomi adalah pertumbuhan terus-menerus dari faktor produksi secara benar yang mampu memberikan kontribusi bagi kesejahteraan manusia. Suatu peningkatan dari faktor produksi tidak dianggap sebagai pertumbuhan ekonomi jika produksi tersebut memasukkan barang-barang yang terbukti memberikan dampak buruk dan membahayakan manusia.

Ranis (2004) menyatakan bahwa pertumbuhan ekonomi memberikan manfaat langsung terhadap peningkatan pembangunan manusia melalui peningkatan pendapatan.

\section{Belanja Modal Manusia}

\section{Belanja Pendidikan}

Menurut Soyomukti

(2008:29) pendidikan masih dipercaya sebagai proses yang mampu memompa tenaga produktif bangsa kita. Maksud dari tenaga produktif disini menurut Soyomukti (2008:31) adalah suatu kemampuan masyarakat untuk menghasilkan suatu bentuk tindakan dan produk-produk baik yang bersifat ekonomis-teknologis maupun intelektualitas. Pada umumnya tenaga produktif masyarakat lebih dikenal sebagai ilmu pengetahuan dan teknologi. 
Putri, et al/Jurnal Ekonomi Syariah Teori dan Terapan Vol. 6 No. 7 Juli 2019: 1410-1420; DETERMINAN ISLAMIC HUMAN DEVELOPMENT INDEX (IHDI) PROVINSI JAWA TIMUR TAHUN 2001-2016

Menurut Soyomukti (2008:31) ketika masyarakat semakin mengalami kemajuan di bidang ilmu pengetahuan dan teknologi, maka di dalamnya banyak individu yang mendapat kemudahan hidup, kesejahteraan dan kemudahan untuk mengekspresikan kemanusiaanya.

Kualitas pendidikan masyarakat menjadi penting dikarenakan pendidikan dapat meningkatkan keterampilan masyarakat dalam bekerja. Pekerja yang tidak terampil meskipun bekerja dengan jam yang panjang maka tetap akan memperoleh pendapatan perkapita yang rendah (Jhingan, 2010:435).

\section{Belanja Kesehatan}

Pentingnya kesehatan membuat sebagian orang memandang sebagai sebuah komoditi yang dapat diperjual belikan. Sebagaimana dalam Tjiptoherijanto (1994:26) kesehatan dalam hal ini adalah pelayanan kesehatan merupakan sebuah komoditi. Kesehatan tidak termasuk komoditi karena dalam Tjiptoherijanto (1994:27) kesehatan hanya memiliki value in use bukan value in exchange.

Schultz dalam Jhinghan (2010:414) mengemukakan bahwa fasilitas dan pelayanan kesehatan pada umumnya diartikan mencakup semua pengeluaran yang mempengaruhi harapan hidup, kekuatan dan stamina tenaga serta vitalitas rakyat. Dengan demikian peningkatan fasilitas pendidikan dan kesehatan suatu negara menjadi sangat penting dan berpengaruh dalam pembangunan manusia di negara tersebut.

\section{Distribusi Dalam Islam}

\section{Zakat Infak Sedekah}

Mazhab Hanafi dalam Effendi (2008:83) mendefinisikan zakat berarti menjadikan sebagian harta yang khusus dari harta yang khusus sebagai milik orang yang khusus, yang ditentukan oleh syariat karena Allah SWT. Kewajiban dalam menunaikan zakat dalam islam wajib bagi seluruh umatnya yang telah memenuhi syarat dalam menunaikannya sebagaimana firman Allah SWT dalam surah Al-Baqarah Ayat 43, yang artinya, "Dan dirikanlah shalat, tunaikanlah zakat dan ruku'lah beserta orang-orang yang ruku'."

Menurut terminologi syariat dalam Latifah (2013) Infak adalah mengeluarkan sebagian harta atau pendapatan (penghasilan) untuk suatu kepentingan yang diperintahkan ajaran Islam. Mengeluarkan infak tidak memerlukan syarat tertentu atau nisab seperti halnya untuk mengeluarkan zakat. Sedangkan pengertian lain daripada infak menurut Sholihin (2010:351) adalah mengeluarkan harta yang mencakup zakat dan non zakat.

Menurut Gaus (2008:21) dalam Fiqhyany (2014), sedekah adalah suatu pemberian yang diberikan oleh seorang muslim kepada orang lain secara spontan dan sukarela tanpa dibatasi oleh waktu dan jumlah tertentu.

Beik (2010) menjelaskan bahwa zakat, Infak, dan sedekah dapat 
mengurangi ketimpangan distribusi pendapatan pada penduduk miskin, sehingga jika terjadi perbaikan dalam distribusi pendapatan akan menyebabkan penduduk miskin memperoleh pendapatan yang lebih baik. Peningkatan pendapatan pada penduduk miskin mendorong mereka untuk membelanjakan pengeluaran rumah tangganya agar dapat memperbaiki kualitas kesehatan dan pendidikan anggota keluarga, yang mana dua komponen itu sangat diperlukan untuk meningkatkan kualitas sumber daya manusia.

\section{Hipotesis dan Model Analisis}

Hipotesis yang digunakan dalam penelitian ini adalah sebagai berikut:

$\mathrm{Hl}$ :Pertumbuhan Ekonomi berpengaruh terhadap Islamic Human Development Index (IHDI) di Provinsi Jawa Timur.

H2: Belanja Pemerintah bidang pendidikan berpengaruh terhadap IslamicHuman Development Index (IHDI) di Provinsi Jawa Timur.

H3: Belanja Pemerintah bidang kesehatan berpengaruh terhadap Islamic Human Development Index (IHDI) di Provinsi Jawa Timur.

H4: Distribusi Dana Zakat, Infak, dan Sedekah terhadap Islamic Human Development Index(I-HDI) di Provinsi Jawa Timur.

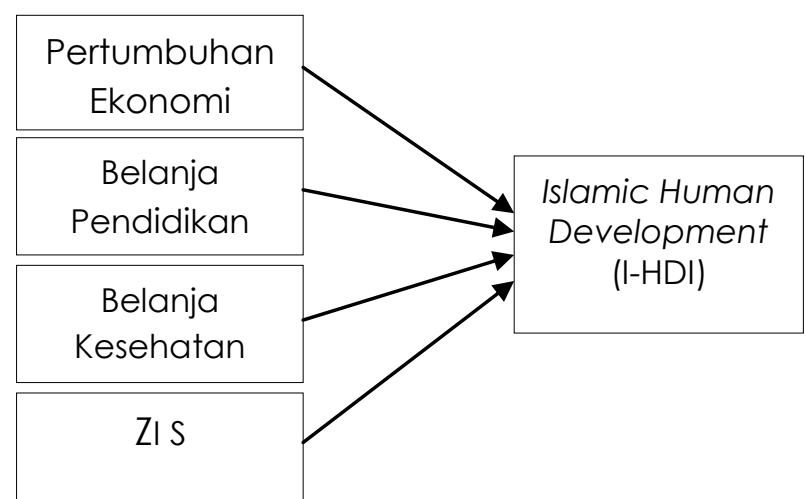

Sumber: penulis

\section{Gambar 1.Model Analisis}

III. METODE PENELITIAN

Jenis penelitian yang digunakan adalah kuantitatif. Pendekatan ekonometri dilakukan untuk menguji hipotesis dengan menggunakan metode analisis Ordinary Least Square (OLS) untuk melihat elastisitas variabel bebas (independent) terhadap variabel terikat (dependent). Pengolahan data dan hasil estimasi model analisis pada penelitian ini menggunakan perangkat lunak Microsoft Excel dan Eviews 7.Variabel terikat adalah Islamic Human Development Index (I-HDI), sedangkan variabel bebas terdiri dari Pertumbuhan Ekonomi (Produk Domestik Regional Bruto (PDRB) Provinsi Jawa Timur menurut harga konstan dan harga dasar berlaku 2010), Investasi Modal Manusia dibidang Pendidikan dan Kesehatan (belanja pemerintah dibidang kesehatan dan pendidikan), dan Distribusi Dana Zakat, Infak dan Sedekah (total dana ZIS yang terdistribusi di BAZNAS Provinsi Jawa Timur)

Penelitian ini menggunakan data sekunder yaitu berupa data runtut waktu atas (time series) dengan kurun waktu dari tahun 2001-2016. Data yang diperoleh dari 
Putri, et al/Jurnal Ekonomi Syariah Teori dan Terapan Vol. 6 No. 7 Juli 2019: 1410-1420; DETERMINAN ISLAMIC HUMAN DEVELOPMENT INDEX (IHDI) PROVINSI JAWA TIMUR TAHUN 2001-2016

berbagai sumber yaitu dari kantor Badan

Pusat Statistik Provinsi Jawa Timur,

Direktorat Jenderal Perimbangan

Keuangan (DJPK) Kementrian Keuangan

Republik Indonesia dan BAZNAS Provinsi Jawa Timur.

Adapun definisi operasional dalam penelitian ini adalah berikut:

1. Islamic Human Development Index (IHDI) adalah angka indeks pembangunan manusia menurut Islam yang merupakan indeks komposit dari indikator non material dan material yang terdiri atas angka kriminalitas, angka melek huruf, angka partisipasi siswa sekolah, angka harapan hidup, angka kelahiran total, angka kematian bayi, rata-rata pengeluaran perkapita disesuaikan, indeks gini, dan indeks kedalaman kemiskinan (P1).

2. Pertumbuhan ekonomi dilihat dari Produk Domestik Regional Bruto adalah keseluruhan nilai tambah barang dan jasa dari berbagai sektor ekonomi di suatu daerah dalam waktu tertentu (Rupiah/tahun). Data PDRB yang digunakan adalah PDRB harga konstan Provinsi Jawa Timur Atas Dasar Harga Berlaku 2010 periode 2001-2016.

3. Belanja pemerintah bidang pendidikan dan kesehatan adalah anggaran yang dikeluarkan oleh pemerintah yang bertujuan untuk memenuhi kebutuhan masyarakat yang tertuang dalam Anggaran Pendapatan dan Belanja Daerah (APBD). Data belanja pemerintah bidang pendidikan dan kesehatan dalam penelitian ini menggunakan data anggaran pemerintah di bidang pendidikan dan kesehatan selama periode 2001-2016 menggunakan harga kostan Atas Dasar Harga Berlaku 2010.

4. Distribusi yang dilakukan oleh Badan Amil Zakat Provinsi Jawa Timur atas jumlah dana yang berhasil dikumpulkan oleh Baznas baik melalui intrumenzakat, infak maupun sedekah. Data distribusi dana ZIS didapatkan dari laman resmi BAZNAS dan melalui surat permohonan penelitian yang telah diajukan secara resmi dari penulis kepada BAZNAS langsung di kantor BAZNAS Provinsi Jawa Timur.

Teknik analisis yang digunakan adalah metode Ordinary Least Square (OLS) untuk melihat elastisitas variabel bebas (independent) terhadap variabel terikat (dependent).

Ada beberapa kriteria untuk menyatakan bahwa model regresi yang dihasilkan adalah baik, yakni (Gujarati, 2003)

1. Kriteria Ekonomi (tanda dan besaran)

2. Kriteria Statistik (Uji $t$, uji F dan R2)

3. Kriteria Ekonometrika BLUE (Best Liniear Unbiased Estimator)

Selain itu dilakukan pula Uji Asums Klask yang berupa Uji Multikolinearitas, Heteroskedasitas, Autokorelasi, dan Uji normalitas

\section{HASIL DAN PEMBAHASAN}

\section{Uji Asumsi Klasik}

\section{Uji Multikolinieritas}

Multikolinieritas variabel dapat dilihat dari koefisien korelasi dari masing- 
masing variabel bebas, jika koefisien korelasi antara masing-masing variabel bebas lebih besar dari 0,8 berarti terjadi mulikolinieritas. Hasil uji mulikolinieritas dapat dilihat pada Tabel 1

Tabel 1.

Hasil Uji Multikolinieritas

\begin{tabular}{cccccc} 
Variabel & IHDI & ANGPEN & ANGKES & PDRB & ZIS \\
\hline \hline IHDI & 1.000000 & 0.787781 & 0.695166 & 0.693766 & 0.787556 \\
ANGPEN & 0.787781 & 1.000000 & 0.693622 & 0.791766 & 0.782240 \\
ANGKES & 0.695166 & 0.693622 & 1.000000 & 0.696622 & 0.791271 \\
PDRB & 0.693766 & 0.791766 & 0.696622 & 1.000000 & 0.695387 \\
ZIS & 0.787556 & 0.782240 & 0.791271 & 0.695387 & 1.000000
\end{tabular}

Sumber: Penulis

Uji Heteroskedasitas

Hasil yang perlu diperhatikan dalam uji heteroskedasitas menggunakan White Heteroskedasticity adalah nilai $F$ dan Obs*R-Squared, jika nilai probabilitas $F$ dan Obs*R-Squared kurang dari $a=1 \%$, $5 \%$, dan $10 \%$ maka Ho ditolak dan $\mathrm{Hl}$ diterima, dengan kata lain terdapat heteroskedasitas begitu sebaliknya. Hasil uji heteroskedasitas dapat dilihat pada Tabel 2.

Tabel 2.

\section{Hasil Uji Heteroskedasitas}

Heteroskedasticity Test: White

\begin{tabular}{llll}
\hline \hline F-statistic & 68.02546 & Prob. F(14,1) & 0.4780 \\
Obs*R-squared & 15.98322 & Prob. Chi-Square(14) & 0.3144 \\
Scaled explained SS & 6.687852 & Prob. Chi-Square(14) & 0.9461 \\
\hline \hline
\end{tabular}

Sumber: Penulis

\section{Uji Autokorelasi}

Hasil yang perlu diperhatikan dalam uji autokorelasi menggunakan Metode Bruesch-Godfrey yang lebih dikenal dengan LM-Test adalah nilai F dan Obs*R-Squared, jika nilai probabilitas $\mathrm{F}$ dan Obs*R-Squared kurang dari $a=1 \%, 5 \%$, dan $10 \%$ maka Ho ditolak dan $\mathrm{H} 1$ diterima, dengan kata lain terdapat autokorelasi begitu sebaliknya. Hasil uji autokorelasi dapat dilihat pada Tabel 3

Tabel 3.

\section{Hasil Uji Autokorelasi}

Breusch-Godfrey Serial Correlation LM Test:

\begin{tabular}{llll}
\hline \hline F-statistic & \multirow{2}{*}{0.072678} & Prob. F(2,9) & 0.3821 \\
Obs R-Rquared & 3.079820 & Prob. Chi-Square(2) & 0.2144 \\
\hline \hline \multicolumn{2}{c}{ Sumber: Penulis } &
\end{tabular}

\section{Uji Normalitas}

Uji normalitas disebut Jarque - Bera Test, jika probabilitas lebih dari pada $a=$ $1 \%, 5 \%$, dan $10 \%$ maka Ho diterima dan $\mathrm{H} 1$ ditolak, dengan kata lain error term terdistribusi normal begitu sebaliknya. Secara rinci untu hasil uji normalitas dapat dilihat pada Gambar 2
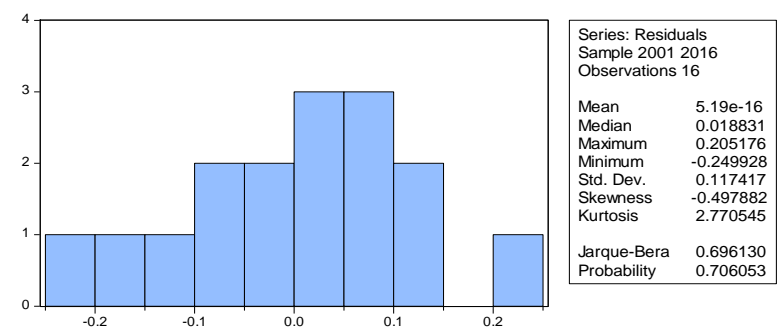

Sumber: penulis

Gambar 2.

Hasil Uji Normalitas

\section{Pembahasan}

Pengaruh Pertumbuhan Ekonomi

Terhadap Islamic Human Development Index (IHDI)

Variabel Pertumbuhan ekonomi

melalui PDRB pada penelitian ini membuktikan bahwa terdapat pengaruh positif yang signifikan terhadap Islamic HumanDevelopment Index (IHDI) di Jawa Timur tahun 2001-2016. Tanda positif pada koefisien menunjukkan hubungan yang searah antara pertumbuhan ekonomi 
(PDRB) terhadap Islamic Human Development Index (IHDI) di Jawa Timur, artinya bahwa ketika pertumbuhan ekonomi (PDRB) naik sebesar satu satuan, maka akan menyebabkan nilai IHDI naik sebesar 0.0896306, dengan asumsi bahwa variabel independen lainnya tidak berubah.

Hubungan pengaruh antara
pertumbuhan ekonomi terhadap
pembangunan manusia telah dijelaskan
oleh Ramirez, dkk dalam Baeti (2013)
menyatakan bahwa pertumbuhan
ekonomi berpengaruh terhadap
pembangunan manusia melalui aktivitas rumah tangga dan pemerintahnya. Pertumbuhan ekonomi merupakan salah satu indikator untuk menilai keberhasilan pembangunan dari suatu negara atau daerah. Pertumbuhan ekonomi berkaitan erat dengan peningkatan barang dan jasa yang diproduksi dalam masyarakat, semakin banyak yang diproduksi itu artinya kesejahteraan masyarakat meningkat. Pertumbuhan ekonomi yang baik adalah pertumbuhan yang disertai dengan distribusi pendapatan agar tidak terjadi kesenjangan sosial.

\section{Pengaruh Belanja Pemerintah Bidang} Pendidikan dan Kesehatan Terhadap Islamic Human Development Index (IHDI)

Hasil Penelitian menunjukkan dimana variabel pengeluaran pemerintah di bidang pendidikan mempunyai pengaruh positif yang signifikan terhadap Islamic HumanDevelopment Index (IHDI) di Provinsi Jawa Timur tahun 2001-2016. Tanda positif padakoefisien menunjukkan hubungan yang searah antara pengeluaran pemerintah di bidang pendidikan dan kesehatan terhadap Islamic Human Development Index (IHDI) di Indonesia, artinya bahwa ketika pengeluaran pemerintah di bidang pendidikan naik sebesar satu satuan, maka akan menyebabkan nilai IHDI naik sebesar 0.161188 satuan, dengan asumsi bahwa variabel independen lainnya tidak berubah. Selanjutnya, variabel anggaran kesehatan juga mempunyai pengaruh positif yang signifikan terhadap Islamic Human Development Index (IHDI) di Provinsi Jawa Timur tahun 2001-2016. Kenaikan sebesar satu satuan pada anggaran kesehatan, maka akan menyebabkan nilai IHDI naik sebesar 0,275851 satuan, dengan asumsi bahwa variable independen lainnya tidak berubah.

Penelitian sebelumnya oleh Mirza (2012) dan Baeti (2013) sesuai dengan hasil penelitian ini bahwa pada variabel belanja pemerintah di bidang pendidikan dan kesehatan berpengaruh positif signifikan tehadap pembangunan manusia. Hubungan positif tersebut dapat diartikan bahwa kenaikan tingkat belanja pemerintah di bidang pendidikan dan kesehatan akan meningkatkan kualitas pembangunan manusia dan diikuti dengan meningkatnya Islamic HumanDevelopment Index (IHDI).

Pengaruh Distribusi Dana Zakat, Infak dan Sedekah Terhadap Islamic Human Development Index (IHDI) 
Hasil Penelitian ini menunjukkan dimana variabel distribusi dana zakat, Infak dan sedekah mempunyai pengaruh yang positif namun tidak signifikan terhadap Islamic HumanDevelopment Index (IHDI) di Provinsi Jawa Timur tahun 2001-2016. Hasil uji † menunjukkan bahwa nilai signifikan ZIS sebesar 0,4246, dimana nilai ini kebih besar dari 0,05 sehingga dapat disimpulkan bahwa Hipotesa dalam penelitian ditolak.

Hasil pengujian ini sesuai dengan penelitian yang dilakukan oleh Nurzaman (2010), dimana Zakat tidak berpengaruh langsung untuk meningkatkan indeks pembangunan manusia, bahkan variabel zakat menunjukkan nilai yang sangat kecil dan secara statistik tidak signifikan pada beberapa komponennya perhitungan pembangunan manusia. Penelitian milik Murniarti dan Beik (2014) juga menunjukkan bahwa setelah pendistribusian zakat pun kualitas sumber daya manusia masih berada pada kondisi rendah.

\section{SIMPULAN DAN SARAN}

\section{Simpulan}

Berdasarkan rumusan masalah dan hasil analisis, maka penelitian ini dapat disimpulkan sebagai berikut:

1. Berdasarkan hasil analisis OLS dapat dijelaskan bahwa setiap ada perubahan $1 \%$ pada variabel PDRB menyebabkan perubahan IHDI sebesar 0,89 satuan dimana variabel lain dianggap tetap; perubahan $1 \%$ pada variabel anggaran pendidikan menyebabkan perubahan IHDI sebesar
0,16 satuan dimana variabel lain dianggap tetap; perubahan $1 \%$ pada variabel anggaran kesehatan menyebabkan perubahan IHDI sebesar 0,27 satuan dimana variabel lain dianggap tetap; perubahan $1 \%$ pada variabel distribusi dana ZIS menyebabkan perubahan IHDI sebesar 0,04 satuan dimana variabel lain dianggap tetap dan jika tidak ada perubahan terhadap variabel PDRB, anggaran pendidikan, anggaran kesehatan dan distribusi dana ZIS maka akan terjadi perubahan IHDI sebesar 0,4 satuan (variabel diluar model).

2. Pertumbuhan ekonomi (PDRB) di Jawa Timur menunjukkan peningkatan barang dan jasa yang diproduksi dalam masyarakat, semakin banyak yang diproduksi berdampak pada peningkatan kesejahteraan masyarakat meningkat melalui kenaikan pendapatan. Pertumbuhan ekonomi memberikan efek yang kuat pada kenaikan dan penurunan kualitas sumber daya manusia yang sesuai dengan Maqashid syariah.

3. Peningkatan pelayanan pendidikan ini secara otomatis akan meningkatkan peluang masyarakat untuk mengenyam bangku pendidikan. Semakin banyak masyarakat yang mendapatkan pendidikan maka akan meningkatkan angka melek huruf dan partisipasi siswa sekolah sebagaimana yang dihitung dalam perhitungan Maqashid syariah Index Al Aql. 
4. Kenaikan belanja pemerintah dibidang kesehatan secara otomatis akan memudahkan masyarakat mendapatkan pelayanan kesehatan yang memadai, sehingga akan kualitas dan derajat kesehatan masyarakat. Kualitas dan derajat kesehatan masyarakat dalam perhitungan IHDI menurut Maqashid syariah diukur dengan melihat angka harapan hidup, angka kelahiran total dan angka kematian bayi per tahunnya.

5. Distribusi dana ZIS belum mampu untuk meningkatkan IHDI. Permasalahan ini disebabkan karena pengelolaan dana ZIS oleh para penerima masih digunakan untuk keperluan konsumsi walaupun pada program BAZNAS provinsi Jawa Timur telah mengelompokkan berdasarkan lima program yang berguna untuk meningkatkan kualitas sumber daya manusia.

\section{Saran}

Berdasarkan hasil penelitian dan kesimpulan diatas, maka terdapat beberapa saran yang dapat direkomendasikan sebagai berikut:

1. Perekonomian Jawa Timur yang melambat dapat berdampak pada pembangunan manusia juga melambat. Padahal, perekonomian Jawa Timur berkontribusi dua per tiga ekonomi Indonesia. Pembangunan manusia (IHDI) ke depan melalui peningkatan PDRB Jawa Timur baik dari sisi penawaran dan permintaan seharusnya dapat meningkatkan pula kualitas sumber daya manusia menjadi semakin baik baik dari segi materiil maupun non materiil.

2. Belanja pemerintah dibidang pendidikan dan kesehatan diharapkan dapat mengoptimalkan anggaran tersebut untuk fokus pada peningkatan kualitas sumberdaya manusia. Seperti pemerataan kelayakan fasilitas pendidikan dan kesehatan baik dikota maupun didesa.

3. Pendistribusian dana ZIS diharapkan saling terkoordinasi antar BAZNAS Pusat, BAZNAS Provinsi, BAZNAS Kabupaten/Kota dan UPZ lainnya. Satu komando akan lebih memudahkan agar pengumpulan dan pendistribusian dana zakat tidak tumpang tindih sehingga sistem komando menjadi lebih tertata dan terkoordinasi.

4. Masih terbatasnya penelitian ini sehingga diharapkan penulis berikutnya dapat memasukan variabelvariabel lainnya dan secara rinci antara wilayah untuk lebih mempertajam dan memperdalam analisis.

\section{DAFTAR PUSTAKA}

Anto, M. Hendrie. 2009. Introducing an Islamic Human Development Index(IHDI) to Measure Development in OIC Countries. Islamic EconomicStudies, Vol. 19 No.2.

Baeti, Nur. 2013. Pengaruh Pengangguran, Pertumbuhan Ekonomi, danPengelvaran Pemerintah Terhadap Pembangunan Manusia 
Kabupaten/Kota Di Provinsi Jawa

Tengah Tahun 2007-2011. ISSN 2252-6889.

Beik, Irfan Syauqi \& Arsyianti, Laily Dwi. 2015. Ekonomi Pembangunan Syariah. Bogor : Penerbit IPB Press.

Effendi, Agus dan Bahruddin Fananny. 2008. Zakat : Kajian Berbagai Mazhab.Bandung. PT Remaja Rosdakarya.

Fiahyany. 2014. Dampak Shadaqah Pada Keberlangsungan Usaha. Surabaya.Skripsi tidak diterbitkan. Universitas Airlangga Surabaya.

Jhingan, M.L. 2010. Ekonomi Pembangunan dan Perencanaan. Jakarta. PT. Raja Grafindo Persada. Mankiw, N. Gregory dkk. 2012. Pengantar Ekonomi Makro Edisi Asia Volume 2. Terjemahan oleh Biro Bahasa Alkemis. Jakarta : Salemba Empat.

Mirza, Denni Sulistio. 2012. Pengaruh kemiskinan, Pertumbuhan Ekonomi, danBelanja Modal Terhadap Indeks Pembangunan Manusia di Jawa Tengah Tahun 2006-2009. Economics Development Analysis Journal. ISSN 2252-6560.

Murniarti, Rina \& Irfan Syauqi Beik. 2011. Pengaruh Zakat Terhadap Indeks Pembangunan Manusia dan Tingkat Kemiskinan Mustahik : Studi Kasus Pendayagunaan BAZNAS Kota Bogor. ISSN 2337-6333.

Naf'an. 2014. Ekonomi Makro: Tinjauan Ekonomi Syariah.Cetakan kesatu. Yogyakarta: Graha llmu.
Nurzaman MS. 2010. Zakat and human development: an empirical analysis on poverty alleviation in Jakarta, indonesia. Center for Islamic economics and finance, Qatar faculty of Islamic studies, Qatar foundation. p 1-26.

Ranis, Gustav. 2004. Human Development and Economic Growth. Working Papers 887. Economic Growth Center. New Harven : Yale University.

Sholihin, Ahmad Ifham. 2010. Buku Pintar Ekonomi Syariah. Jakarta. PT Gramedia Pustaka Utama.

Soyomukti, Nurani. 2008. PendidikanBerperspektif Globalisasi.Yogyakarta. Ar-Ruzz Media. 